\title{
El cuerpo femenino como territorio sagrado. Una interpretación de la ritualidad sobre la piel entre las indígenas huastecas del oriente de México ${ }^{1}$
}

\section{The feminine body as a sacred territory. An interpretation of rituality on the skin among the indigenous huastec women from Eastern Mexico}

\author{
Claudia Rocha Valverde ${ }^{2}$ \\ Uno piensa, siente y se comporta, de principio a fin, sustentado en la tierra \\ (Anita Brenner, 1983, p. 116).
}

\begin{abstract}
Resumen
La Huasteca Potosina es una región al oriente de la república mexicana en la que se desarrollaron pueblos de gran relevancia sociocultural dentro del complejo conocido como Mesoamérica. Este texto se propone un estudio del contexto cosmológico del pueblo huasteco en el culto a distintas deidades entre las que destacaremos el concepto de 'Madre Tierra' y su vínculo con la fertilidad. Para ello se analizan distintas formas de representación artística, entre las que destacan los códices, esculturas y vasijas efigie de terracota, a partir de las cuales se plantea la hipótesis de que el cuerpo femenino fue considerado un espacio sagrado adornado con pintura, tatuajes y vestimentas específicas que le dieron identidad simbólica y estética.
\end{abstract}

Palabras claves: vestimenta, sagrado, teenek, Madre Tierra, dhayemlaab, ancestral, tatuaje, fertilidad, sagrado.

\begin{abstract}
The Huasteca Potosina is a region to the east of Mexico where cultures of great socio cultural relevance developed within a compound known as Mesoamerica. The purpose of this text is to develop a study of the cosmological context of the huasteco people in which such people rendered tribute to different deities, among which we will highlight the concept of Mother Earth and it's link to fertility. For that purpose we consider different artistic ways of representation like codex, sculpure and clay pots from where we propose the feminine body was transformed in a sacred space ornamented with painting, tatoos and specific costumes that gave it a simbolic and aesthetic identity.
\end{abstract}

Keywords: dress, sacred, teenek, Mother Earth, dhayemlaab, ancestral, tatoo, fertility.

Recibido: 29 mayo 2016. Aceptado: 24 noviembre 2016

1 El presente trabajo es un avance de investigación de un proyecto en ciernes sobre la ritualidad expresada en torno al adorno del cuerpo femenino entre los mexicanos de la antigüedad.

2 El Colegio de San Luis, AC, Parque de Macul 155, Fracc. Colinas del Parque, CP. 78299, MÉXICO. Email: rochaclau@yahoo.com 


\section{Introducción}

Hay diversas formas de conocer la identidad cultural de un pueblo que tiene una historia ancestral; esto es posible mediante el estudio de las prácticas mágico-religiosas que le dan cohesión y una forma particular de percibir el universo. Entre éstas, cabe mencionar una serie de rituales que los pueblos antiguos de México desplegaron en torno al culto de deidades vinculadas a la fertilidad, con el propósito de mantener una relación de reciprocidad con los dueños de la naturaleza para proveerse de suficiente alimento y que los embates de sus fuerzas no fueran tan violentos. Con el paso del tiempo esto propició un saber ancestral que consistía en ofrendar y regresar a la tierra lo que le había sido tomado; ello, a través de ceremonias de pedimento y devolución. En este tipo de cultos figuraron personajes femeninos que simbolizaron la maternidad, así como quehaceres específicos que desde épocas remotas eran de competencia femenina. Estas deidades fueron representadas en piedra, barro y códices en los que se destacaron algunas de sus cualidades diferenciadas por medio de la indumentaria y sus componentes, tales como el tocado, la falda, el vestido y distintos abalorios, las manos sobre el vientre y los dibujos pintados sobre el mismo cuerpo, entre otros rasgos.

El culto a las deidades femeninas se comprende dentro de la cosmogonía de los pueblos del México antiguo a través de la subsistencia de testimonios en la forma de distintas expresiones del arte, además de la pervivencia de algunos de estos pueblos hasta la actualidad. Gracias a lo anterior, hemos podido emprender estudios para aproximarnos a las particularidades del pensamiento simbólico que ha dotado de sentido y significado a la totalidad de la vida indígena.

De estas expresiones artísticas -algunas prácticamente en extinción-, se conoce el trabajo plumario, el trabajo de los tlacuilos, el arte en piedra, la cerámica, la joyería y la refinada actividad de confeccionar la indumentaria para la nobleza de la época.

Cabe decir que entre ellas la que mejor se conoce, gracias a los estudios emprendidos hasta el momento, es la indumentaria femenina. Entre otros factores, se debe a la historia de su simbolismo, la tecnología con la que se confecciona y a la indudable belleza de los tejidos. Este tipo de arte y su perseverancia de uso y confección como expresión del pensamiento simbólico reflejado en la historia mítica de los tejidos son una tradición que prevalece hasta el día de hoy, no obstante, su transformación a lo largo de los siglos primeros de conquista y la posterior colonización. No tuvieron igual suerte la práctica del tatuaje, la escarificación, la pintura sobre la piel, la mutilación, la transformación del cráneo y los dientes, todas consideradas formas de arte aplicadas directamente sobre el cuerpo para la representación de diosas y de mujeres nobles.

Este estudio se emprende a partir de un contexto cultural huasteco que dio suma importancia al culto de la fertilidad, que simbolizó la idea de la Madre Tierra y sus representaciones en figuras femeninas que funcionaron como el soporte material para expresar esta relación mito-histórica.

\section{Aproximación histórica}

La historia de los huastecos al noreste de México se comprende mejor en el contexto mesoamericano, el cual puede explicarnos a grandes rasgos algunos de los elementos que tenían en común los pueblos de esta gran área que comprendía la mitad de México, hasta Guatemala, Belice, Nicaragua, El Salvador y Honduras en Centroamérica. La matriz cultural que compartían se relacionaba con el hecho de que sus pueblos poseían una serie de características socioculturales que pertenecían a una misma cosmovisión sistémica. De éstas puede mencionarse un amplio corpus mitológico, la indumentaria femenina y masculina con sus objetos suntuarios, a los que daban suma importancia. También la creencia en un orden universal regido por un centro y cuatro rumbos cósmicos, solo por mencionar algunos de sus aspectos. Esto nos permite entender en la actualidad cómo es que se han organizado estas manifestaciones y la manera en que siguen presentes en la vida de los pueblos sobrevivientes al período de colonización.

Respecto al pueblo huasteco de filiación mayense apegado al desarrollo cultural mesoamericano, en lo que respecta al listado anterior, Johansson 
(2012) refiere que "el término 'huasteco', derivado del vocablo náhuatl cuexteca, cualquiera que haya sido su significado, no corresponde a una unidad socio-política, sino que designa a distintas naciones indígenas de una región extensa que tenían rasgos culturales comunes" (p. 84).

Según los vestigios arquelógicos y datos de investigaciones sobre la región huasteca del estado de San Luis Potosí, los teenek, que pertenecieron a una de las naciones huastecas, tienen un origen de hace unos tres mil años, período desde el cual existen vestigios que testimonian la importancia simbólica de las cualidades femeninas vinculadas al poder fecundador de la Madre Tierra, una de las deidades supremas.

Lo anterior se basa en la historia de pueblos de pasado remoto que han fincado su desarrollo y evolución con base en una relación equilibrada con las fuerzas de la naturaleza, a las que han dotado de cualidades simbólicas que impactaban de manera directa en el bienestar de estas sociedades. Dichas fuerzas han sido denominadas según su naturaleza, sus posibilidades generadoras de vida y su opuesto complementario, visto también desde su capacidad destructora. De esta manera, sabemos que en el imaginario indígena del México contemporáneo hay una serie de poderosos habitantes sobrenaturales que, en mayor o menor medida, han sido objeto de importantes ofrendas acompañadas de rezos en el contexto de ceremonias específicas.

Entre los teenek existen una serie de expresiones religiosas que han resistido a lo largo de cientos de años al proyecto evangelizador instaurado durante la Colonia, el cual, en un principio, prohibía cualquier manifestación religiosa no vinculada a la Iglesia católica. Por lo tanto, el hecho de que los indígenas consideraran que el universo se constituía por fuerzas diversas e importantes, fue calificado como pensamiento politeísta y, en consecuencia, una práctica idolátrica que se contraponía a la existencia de un Dios único. Es interesante observar que entre los indígenas las fuerzas de la naturaleza, más que considerarse deidades, eran imaginadas como los dueños de éstas. Es así que nos encontramos con la denominación de Dueño del monte y los truenos, el Dueńo del sol, del inframundo y de la tierra, por nombrar algunos.

Entre estos dueños con características específicas hay una diferenciación entre lo femenino y lo masculino. Respecto a ello, intentamos destacar el papel de una de las deidades femeninas supremas en el concepto que tienen de la Gran Madre Tierra y su relación con las mujeres en lo que se refiere a elementos históricos y simbólicos que las identifican.

\section{El cuerpo mítico}

La idea de la desnudez humana ha servido para ataviarla ricamente. El cuerpo de una mujer o de un hombre es concebido para significarlo mediante un complejo sistema indumentario -conformado por diversas prendas, abalorios y tocados en la cabeza, ya sean para el uso cotidiano o ritual- al que los pueblos del México antiguo otorgaron suma importancia simbólica. Es interesante el tratamiento del cuerpo entre las mujeres y los hombres huastecos, ya que, como señala Johansson (2012), "la costumbre que los hombres huastecos tenían de andar desnudos propició la construcción de una imagen arquetípica que trascendió el aspecto 'costumbrista' para adquirir una dimensión claramente simbólica" (p. 92). El cuerpo desnudo, por consiguiente, se convierte en un soporte de diversas expresiones simbólicas y artísticas que crearon identidades específicas.

De esta manera, la desnudez fue simbolizada no tanto a partir de una idea de desinhibición, puesto que sabemos que el concepto de pudor fue una construcción ideológica de la religión cristiana, impuesta a partir de la Conquista. Lo que nos interesa resaltar es el uso que los antiguos mexicanos dieron al cuerpo para construir su propia identidad. Unos pueblos más que otros, en las sociedades prehispánicas existió una práctica diversificada de "intervenirlo", lo cual se tradujo en un conjunto de expresiones artísticas complejas que funcionaron como indicativo de una necesidad cultural, por lo tanto religiosa, de exponer la desnudez "vestida" en distintos tratamientos. Al hablar del uso e intervención del cuerpo nos referimos a los recursos estéticos que desarrollaron en la antiguedad para transmitir algún código. Entre ellos se pueden mencionar los más relevantes por 
su grado de temporalidad y radicalidad en distintas partes del cuerpo. Estos recursos de intervención pueden clasificarse conforme a la técnica con la que se aplicaban, según se identifica entre los huastecos que habitaron el oriente de México, para establecer su vínculo con el arquetípico símbolo universal de la fertildad en la Madre Tierra.

Entre las representaciones femeninas de origen huasteco que encontramos en los vestigios arqueológicos de tipo pictóricos, cerámicos y líticos, observamos cinco formas de manipular el cuerpo por medio de las cuales se realizaban dibujos. En primer lugar, puede mencionarse el uso de pintura con la intención de exponer diseños directamente sobre la superficie de la piel. Otras modalidades de adornar el cuerpo son el tatuaje, la escarificación, la deformación de algunas partes del mismo, además de la forma histórica y universal de tratar la desnudez al cubrirla con distintas prendas textiles. Estas distintas maneras de adornar el cuerpo constituyen una forma de construcción de la identidad femenina.

Existen diferentes ejemplos para observar el tratamiento de la desnudez femenina desde períodos anteriores a la conquista de los espańoles. Un vasto repertorio del arte indígena nos permite establecer los orígenes míticos de las diversas prácticas que fueron adoptadas para dotar al cuerpo femenino de un simbolismo particular identificado en las representaciones de las deidades femeninas.

Entre las deidades relevantes de la cosmogonía indígena huasteca podemos mencionar un personaje emblemático cargado de significados femeninos en la figura de Tlazolteotl Ixcuina, a la que se atribuyen varias e interesantes cualidades mitológicas, entre las que destacan las transgresiones morales como la lujuria, el adulterio, el sexo. Era la diosa lunar de la inmundicia, diosa madre de la fertilidad, conocida también como la gran paridora, a la que se ha representado con diversos elementos decorativos según los cánones estéticos del pueblo que la reproducía. En esta deidad femenina cada prenda y abalorio poseía connotaciones simbólicas que la vinculaban a la práctica ancestral y primigenia del tejido. Todos estos elementos constituyeron en su momento un sistema que permitió descifrar su identidad cósmica, ya que simbolizaba la renovación de la vida, por lo que puede considerarse uno de los arquetipos de la Gran Madre para los pueblos mesoamericanos.

Este personaje femenino está representado en un amplio corpus de esculturas de piedra y en códices, uno de cuyos ejemplos se encuentra en el Códice Borbónico (Figura 1), donde aparece dando a luz en algunos de sus pictogramas, hecho que testimonia sus cualidades indiscutibles de "Gran madre fértil". En el Códice Borgia (Figura 2) se muestra con un tocado en la cabeza, en el que se aprecian implementos textiles tales como el huso y una madeja de algodón, razón por la que se le atribuye la invención del tejido y el bordado.

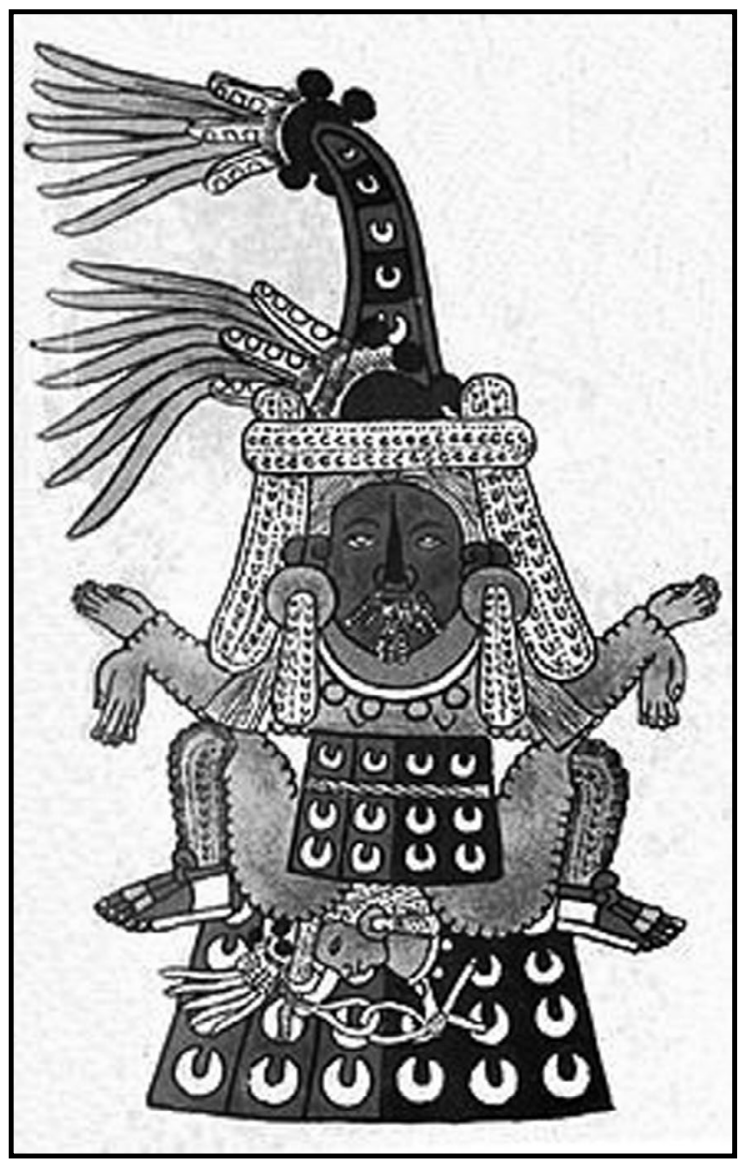

Figura 1. Tlazolteotl Ixcuina. Códice Borbónico, lámina 13. Fuente: El ciclo de la vida. Las edades del hombre en Mesoamérica. Revista Arqueología Mexicana, X(60),17. 


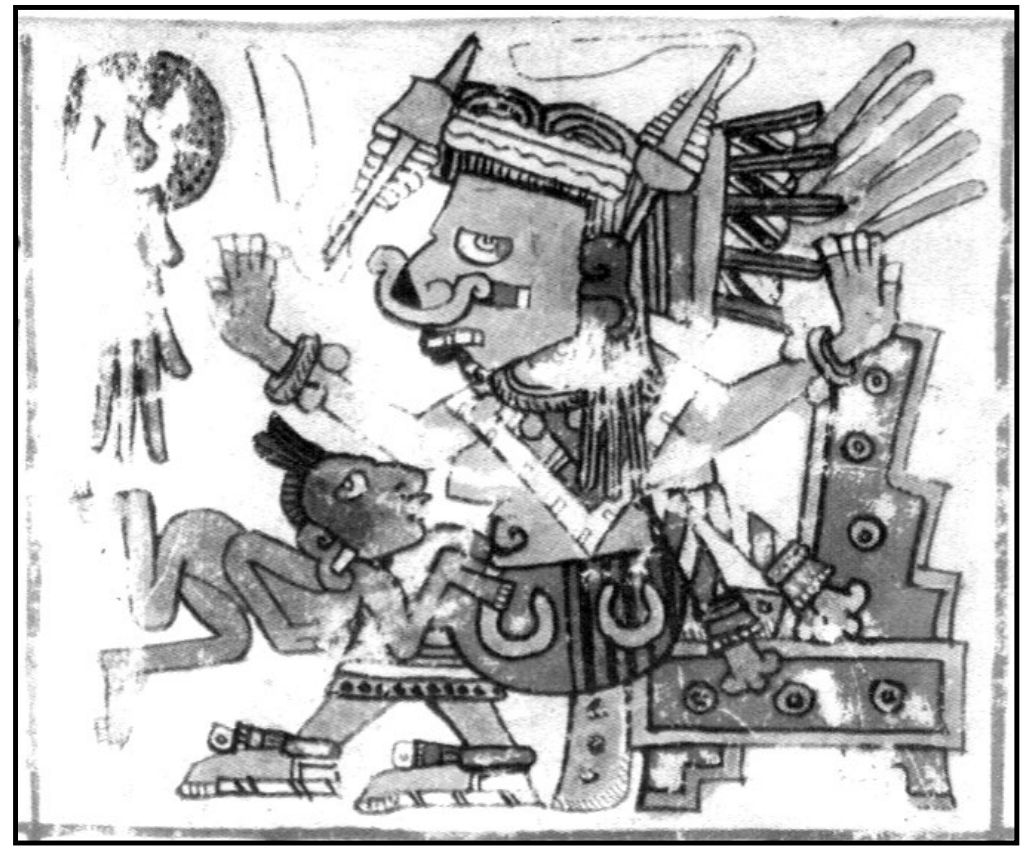

Figura 2. Tlazolteotl. Diosa de las Inmundicias. Diosa de la Tierra. Fuente: Eduard Seler (1963). Comentarios al Códice Borgia, lámina 16. México: Fondo de Cultura Económica.

A esta diosa se le identificaba también por la utilización del quechquemitl, ${ }^{3}$ una prenda usada sobre el torso, que tuvo amplia distribución en la zona media de México, además de un importante uso ritual entre los huastecos. De igual forma, en otros códices como el Fejérváry-Meyer (Figura 3), se le representaba con los pechos desnudos pero con un enredo, ${ }^{4}$ que es la falda de la indumentaria indígena, adornado de una serie de dibujos. Éstas son las dos formas más comunes de representación de las deidades femeninas: con todo el cuerpo ataviado de ornamentos y prendas textiles, o bien, desnudo el torso

3 Prenda ampliamente difundida y usada en Mesoamérica, con forma de rombo. La palabra quechquemitl viene del náhuatl y significa vestido y cuello. Entre el pueblo teenek de origen huasteco, se le denomina dhayem o dhayemlaab.

4 Esta prenda indígena, bastante común en el área mesoamericana, era tejida en telar de cintura con hilo de algodón y, posteriormente, de lana, una vez introducida en América por los españoles. Los pueblos originarios de México que aún la confeccionan, tejen un rectángulo recto de unos siete metros que cosen por sus extremos. Para usarla las mujeres hacen una serie de dobleces por enfrente de la cintura y la ciñen con una faja tejida de igual forma.

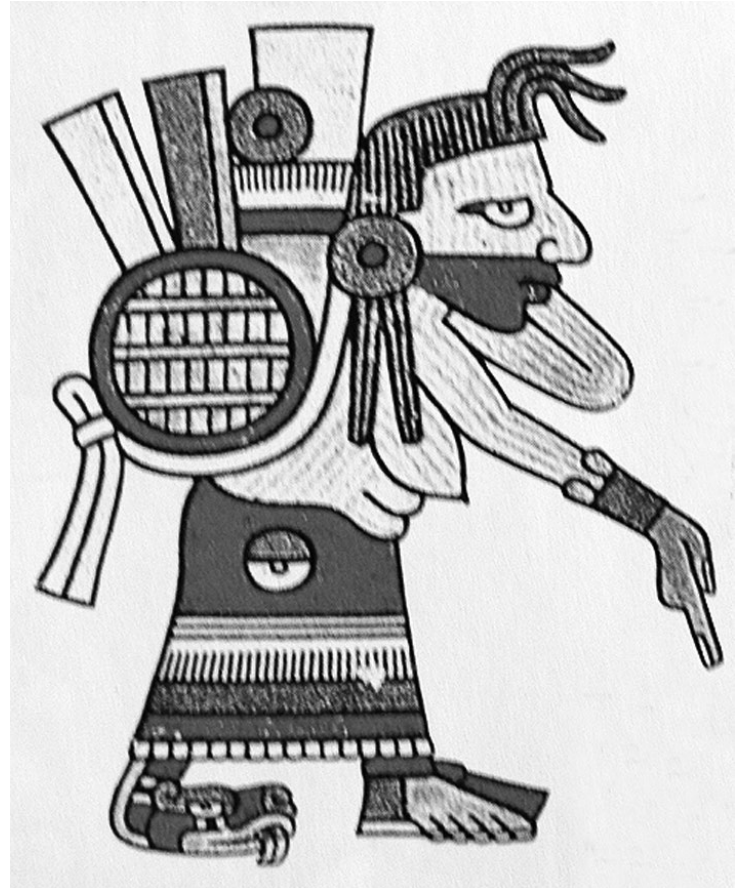

Figura 3. Tlazolteotl Ixcuina. Códice Fejérváry-Mayer. Fuente: Patricia Rieff Anawalt (2005). Atuendos del México antiguo. Revista Arqueología Mexicana, edición especial Textiles del México de ayer y hoy, 19, 16. 
pero con otros abalorios simbólicos y el enredo. Lo que también puede apreciarse en estos códices es el uso de pintura corporal. En el caso de Tlazoltéotl es característica una línea negra a la altura del mentón.

El arte esculpido en piedra -en el que los huastecos fueron prolijos y refinados- se caracterizaba por una sobriedad, un cuidado del cincelado y una pulcritud impactantes; aun al tratarse de figuras tatuadas, no se percibe abigarramiento en la cantidad de elementos que cincelaban para relatar historias míticas. Un ejemplo de ello es la escultura estilizada de

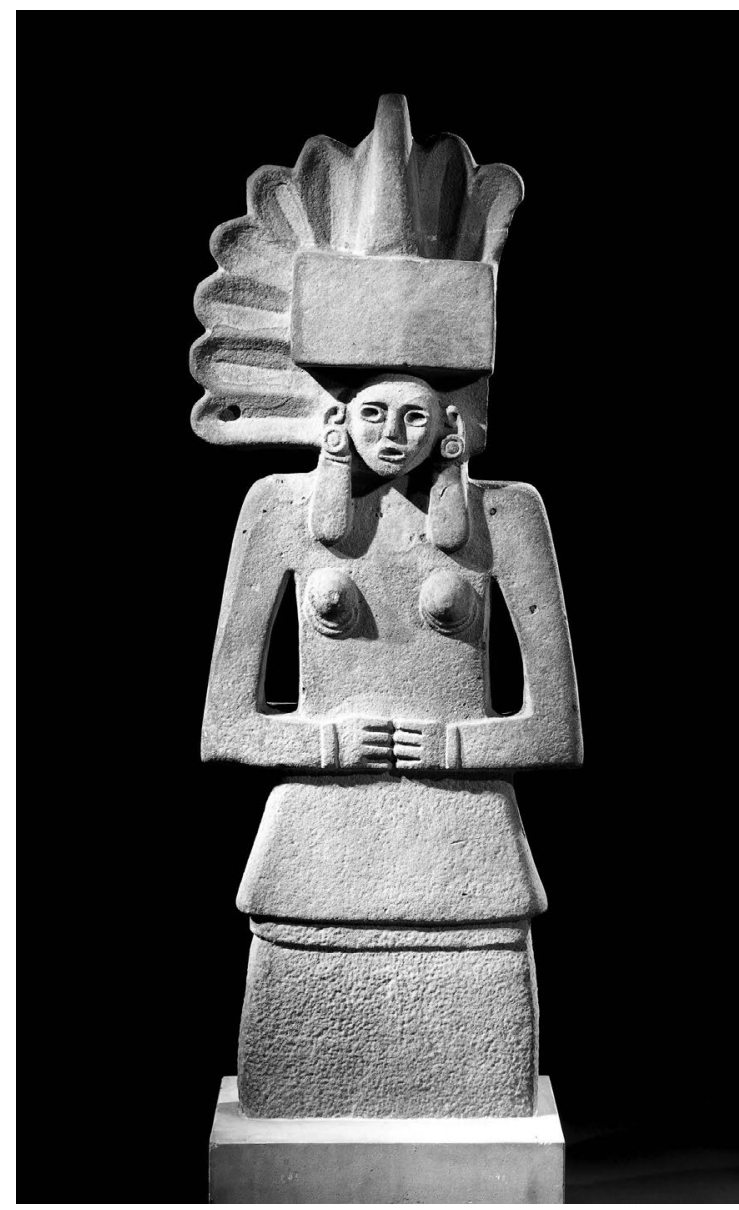

Figura 4. Huaxtec statue of Tlazolteotl from Mexico, 9001521 CE (British Museum, id: Am1989,Q3)

Female figure made of sandstone, standing (truncated), hands folded in front, with fan-shaped (plumed?) headdress having centre-piece in form of cone on top of section of cylinder; left-hand proper edge of head-dress lost. Figure emerge from oblong base.
Tlazoltéotl (Figura 4), de estilo evidentemente huasteco, en la que se observa un tocado en forma de penacho con un cono al centro, elemento estilístico que identificó a los huastecos. Otro componente de este estilo en la Figura 4 son las orejeras y los largos pendientes. Como podemos constatar, este tipo de esculturas femeninas solían crearse con el torso desnudo y un faldón que cubría la parte inferior del cuerpo. Un rasgo adicional que identificaba a las diosas de la fertilidad, era la posición de las manos con las palmas abiertas hacia el vientre (Figura 5 a y b). Tlazolteotl Ixcuina es un prototipo que nos explica la dimensión estética y simbólica de los atributos femeninos, a partir de la significación de la desnudez mediante la ornamentación y la vestimenta de algodón, incluso si se trata tan solo de una prenda. Ello puede deberse a que el atuendo femenino revistió importantes connotaciones cósmicas y también a que en la región huasteca hubo una producción notable de lienzos de algodón.

Hemos visto de qué modo el arte indígena expresado en los códices y la escultura en piedra de los huastecos desde el Preclásico constituyen una forma de testimonio que nos permite develar el pensamiento simbólico en cuanto a la importancia que dieron al cuerpo humano. Al igual que con la escultura, la desnudez entre los huastecos pudo ser labrada, tatuada, pintada y adornada con la indumentaria. La desnudez femenina en su totalidad pudo estar desprovista de significado hasta el momento en que se dibujaba y cincelaba sobre ella. Las representaciones de la media desnudez femenina de las diosas pintadas y en piedra a las que hemos hecho referencia hasta ahora, nos permiten inferir que las mujeres huastecas no iban totalmente desnudas, como se cree que sucedió con los hombres.

En este sentido, surge la pregunta de por qué si en la cosmovisión de los huastecos se encuentran presentes figuras míticas femeninas relacionadas con la fertilidad sexual y agrícola y vinculadas al modelo universal de la Gran Madre que se reproduce y alimenta a su pueblo, no se evidencia la desnudez femenina en su totalidad. Muchas de estas representaciones se encuentran en las condiciones de media desnudez señaladas; un ejemplo más de esto se evidencia en una escultura femenina, en la que tampoco se exponen los órganos sexuales, registrada por De la 




Figuras 5 a y b. Tlazolteotl, cultura huasteca. Posclásico tardío. Tempoal, Veracruz Tlazolteotl, cultura huasteca. Posclásico tardío. Tepetzintla, Veracruz

Fuente: Revista Arqueología Mexicana, edición especial Tocados y peinados en el México antiguo, 66, 57

Fuente (1980) (Figura 6), quien menciona que "su forma general es la de un huso" (p. 70), un utensilio textil; no obstante, desconocemos si la escultura se asocia a dicha actividad. En la parte posterior presenta el tallado de una faja a la altura de la cintura y un tocado de dos paños colgantes.

Lo que nos indica la femineidad en la escultura es la presencia de los pechos expuestos y el uso de algún elemento textil, pues de otra manera podrían considerarse como seres asexuados, al contrario de la representación escultórica varonil en la que los genitales tuvieron un importante valor visual además del simbólico. Fue distinto el tratamiento que dieron al cuerpo masculino en la forma de exponer la desnudez, y esto puede explicarse en el culto que desarrollaron en torno al falo, por lo que quizás consideraron el área genital como expresión de su capacidad fecundadora. La particular predilección de los huastecos por la desnudez que exponen algunos autores, se señala como una de las características que definió la identidad masculina en la antigüedad. A este respecto Johansson (2012) refiere lo siguiente:

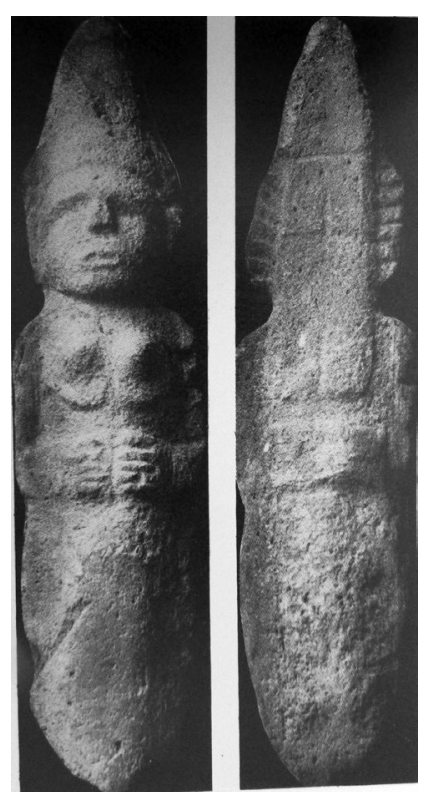

Figura 6. Figura femenina con el torso desnudo y gorro cónico. Museo Regional Antropológico de Tuxpan, Veracruz, p. 70. Láminas LXVIIIa y LXVIIIb, p. 27.

Fuente: Beatriz de la Fuente y Nelly Gutiérrez Solana (1980). Escultura huasteca en piedra. México: UNAM. 


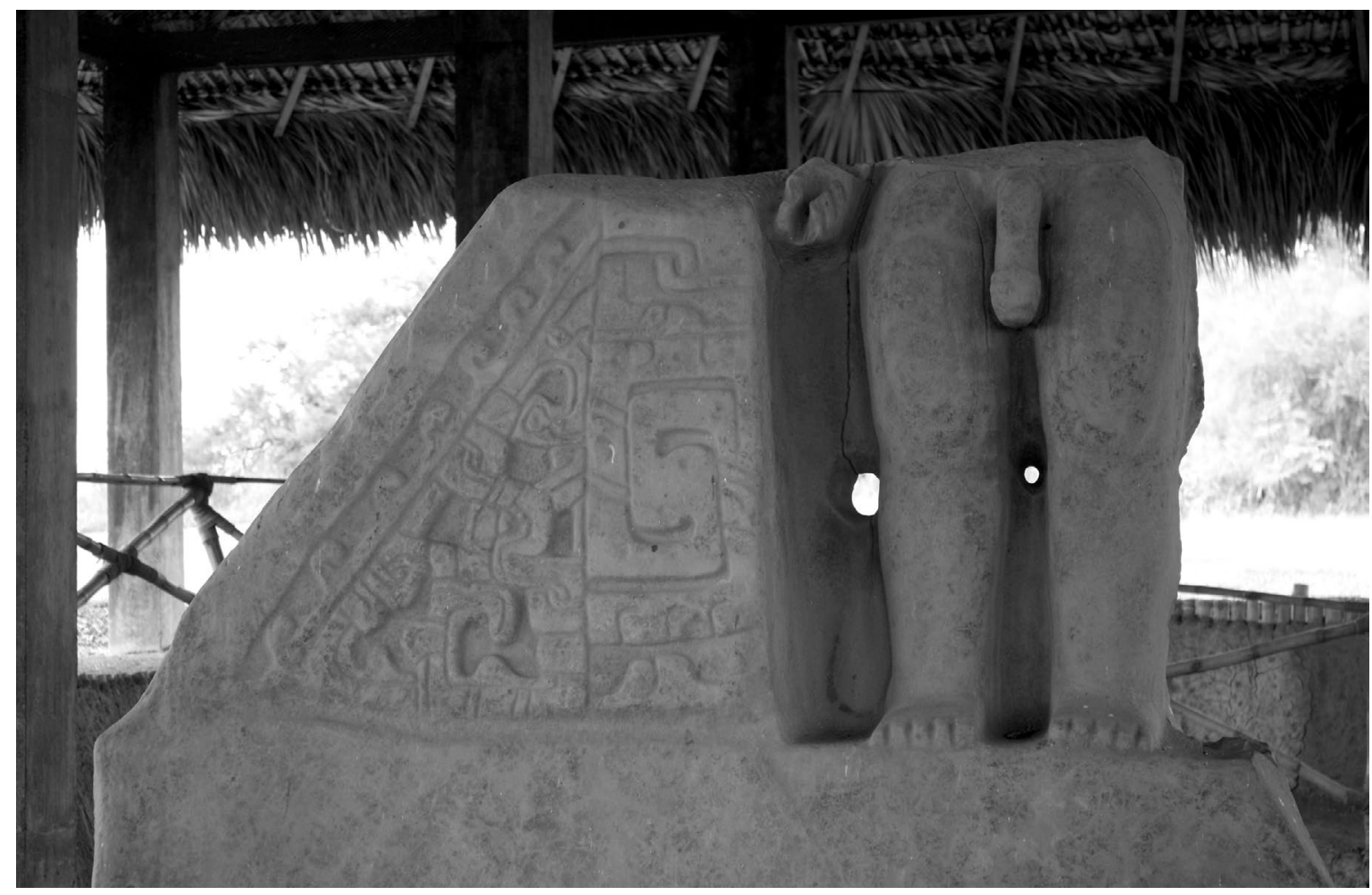

Figura 7. El Gobernante (o simplemente Tomás). Sitio arqueológico de Tamtok, San Luis Potosí, México. Cortesía del Proyecto: Origen y Desarrollo del Paisaje Urbano de Tamtoc, SLP.

Estela Martínez Mora

Si bien, como lo hemos señalado, el hecho de andar sin taparrabo podría haberse debido al clima cálido de la región huasteca, la persistencia de esta costumbre en una cultura tan elaborada y que contaba con tejidos finos, tiene que radicar en una convicción socio-religiosa. Es preciso distinguir dos aspectos de la desnudez: una que representa la ausencia total de atributos indumentarios... (p. 91)

La desnudez masculina fue un tema ampliamente desarrollado en el arte escultórico huasteca, como señala el autor; se manifestó explícitamente, sin requerir que ciertas partes del cuerpo aparecieran cubiertas por prendas. Los adornos no eran una condición para la exposición del cuerpo desnudo. Puede considerarse que la desnudez masculina era el estado ideal para lucir otro tipo de atributos. Como dice Johansson (Ibíd.), "permite ostentar partes erógenas del cuerpo", una forma de culto a la sexualidad y sus connotaciones relativas a la fertilidad de la tierra. En este aspecto es plausible sugerir que la desnudez en el área mesoamericana pudo ser más habitual entre los hombres que en las mujeres, al menos en lo que respecta a los huastecos. Los relatos mito-históricos que refieren al gusto por el cuerpo desnudo y las representaciones de la escultura en piedra de destacado auge entre los huastecos muestran mayoritariamente ejemplos de varones sin vestimenta ni abalorios (Figura 7), en los que más bien la intención fue destacar el área genital dotada de penes de gran tamańo que aludían a la sexualidad y, por lo tanto, a su facultad potencial de inseminar "algo", el cuerpo femenino para reproducirlo y volverlo "Madre" que perpetuara a su pueblo. Además, la desnudez masculina total significaba el opuesto complementario que requería la Madre Tierra en su concepción cósmica para regenerarse a través de los tiempos.

El hecho de destacar particularmente la desnudez en los hombres, como se ha visto en los ejemplos anteriores, no podemos atribuirlo necesariamente al predominio de un patriarcado, o que el culto al falo fuera atribuible a una falocracia en la extensión 
del término. Sin embargo, Luján (2008) señala que "este proceso de distorsión de los símbolos de la sexualidad en relación al placer y la reproducción humana se orientó al afianzamiento del falo como principio vital, degradando y subestimando la función de la mujeres en la procreación" (p. 37). No intentamos dirimir si el papel femenino estuvo en condiciones equitativas al de los varones, o si lo relativo a la femineidad quedó subyugado en algún período de la antiguedad huasteca, como señala Solares (2007) al referirse a "un mundo cada vez más patriarcal y brutalmente guerrero promovido por los aztecas durante el Posclásico" (pp. 14-15). Lo que se intenta proponer es, por lo pronto, que las expresiones estéticas de la época ponderan lo masculino por sobre lo femenino, no obstante se trate llanamente de un estilo escultórico del arte de la región y de una época.

El aspecto sexual de la escultura femenina quedó representado en los pechos de las deidades; sin embargo, cabe mostrar los pocos ejemplos encontrados para este texto que evidencian la escultura con los órganos sexuales femeninos expuestos de igual forma como sucedió con lo masculino. En el caso de lo femenino queda demostrado con la exposición de la vulva, como se aprecia en una figura cerámica (Figura 8) identificada como "mujer en posición de parto". Un segundo y raro ejemplo es el de un personaje en actitud -al parecer- de exposición deliberada (Figura 9), no sabemos si en un acto transgresor, misma que Luján (2007) describe: “...una mujer muestra su vulva en una posición constreñida y grosera, y donde la lanza o bastón que porta le confiere a la escena un ambiente de belicidad" (p. 38 ), escena que a fin de cuentas consuma el simbolismo de lo femenino al que se refiere Solares (2007) al consignar que:

La sensualidad del cuerpo femenino, su poder de seducción y su capacidad de dar a luz, consideramos, no son meras metáforas. Por el contrario, para las culturas antiguas, constituían una revelación, hierofanía, o expresión de la numinosidad contenida en el cuerpo de la mujer, tal y como se resguarda en la historia del arte de los tiempos (p. 15).

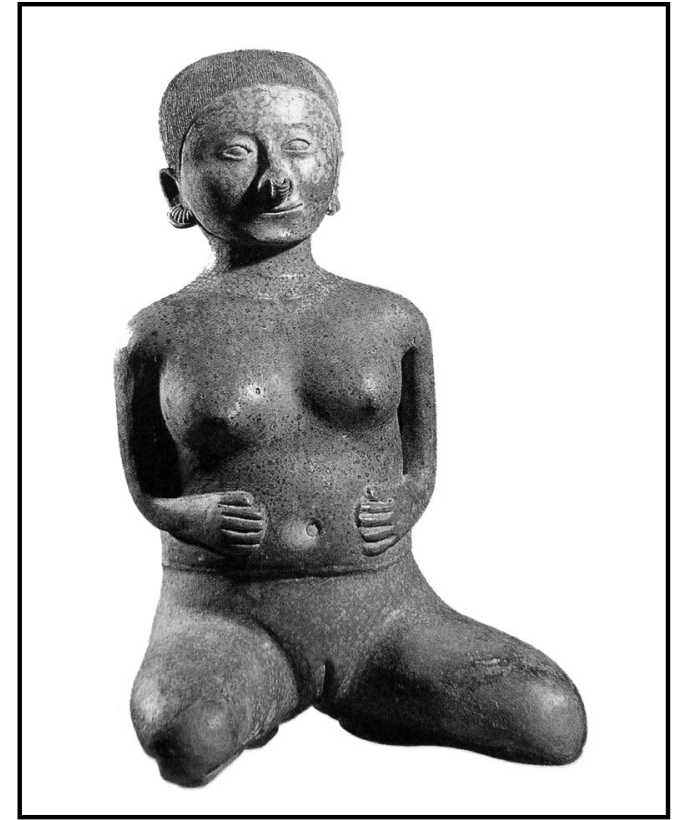

Figura 8. Mujer en posición de parto. Cultura Tumbas de Tiro. Nayarit. Museo Nacional de Antropología Fuente: Los Huastecos. Revista Arqueología Mexicana, XIV(79), 26.

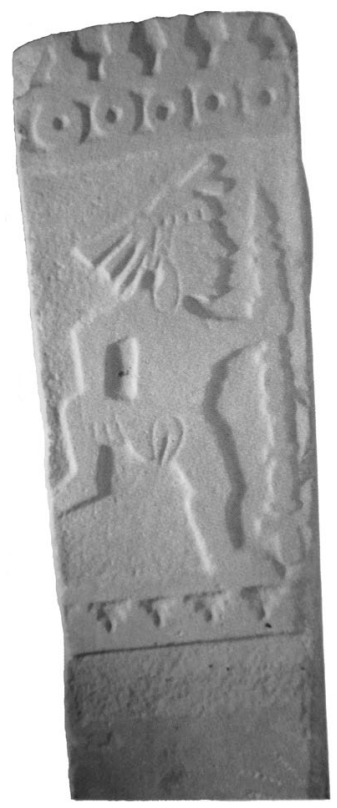

Figura 9. Personaje femenino con bastón (no señala su origen).

Fuente: Sara Ladrón de Guevara y Maliyel Beverido (2008). Mujeres de antaño. Presencias y omisiones, Museo de Antropología de Xalapa (MAX), p. 38. 
a)

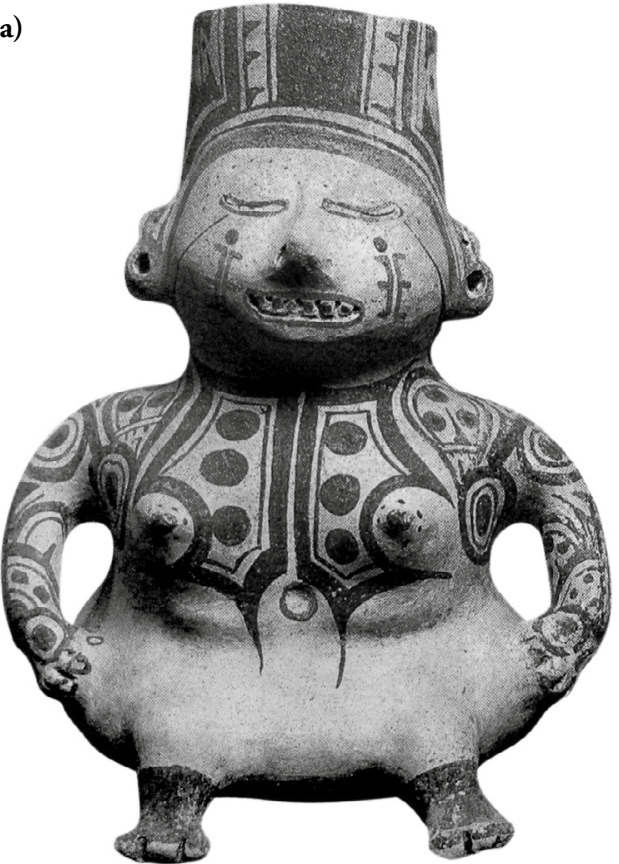

\section{Las vasijas tatuadas}

Otra forma de arte de la cultura huasteca fueron las vasijas cerámicas zoomorfas y antropomorfas, entre las que destacan los cuerpos femeninos de pechos puntiagudos y otros menos prominentes y redondeados (Figura 10 a, b y c). Morfológicamente son vasijas-efigie huecas que en la parte posterior tienen un asa, "la gran mayoría corresponde con creaciones únicas en las que el personaje representa la totalidad de la forma [...] de una función incierta" (Ruiz de la Cruz et al., 2012, p. 318). La parte inferior de estos objetos antropomorfos son asexuados, no hay vulva, solo el remate redondeado del objeto cerámico.

Esta expresión del arte huasteco nos remite a la metáfora del cuerpo como un recipiente, y si consideramos las cualidades de lo femenino en la cosmovisión del antiguo México, las mujeres pertenecían a la parte del universo de condición fría y húmeda; de la oscuridad que gobernaba la luna, opuesto a lo solar y cálido. Una vasija equivale a la matriz b)

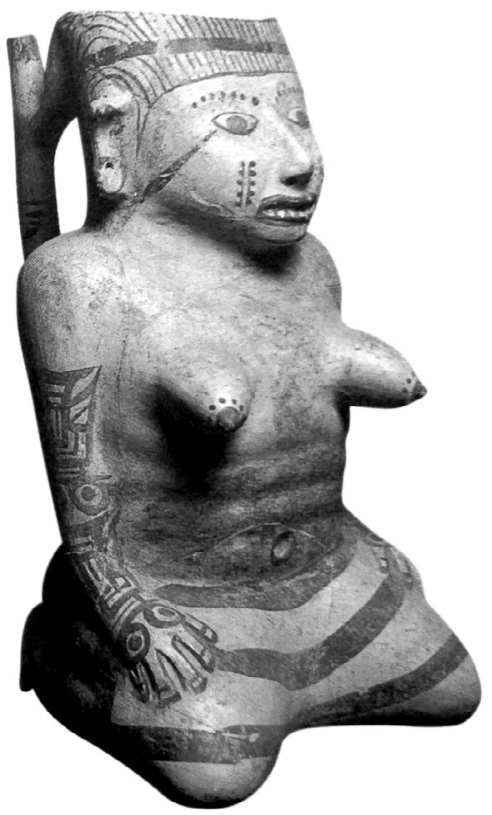

c)

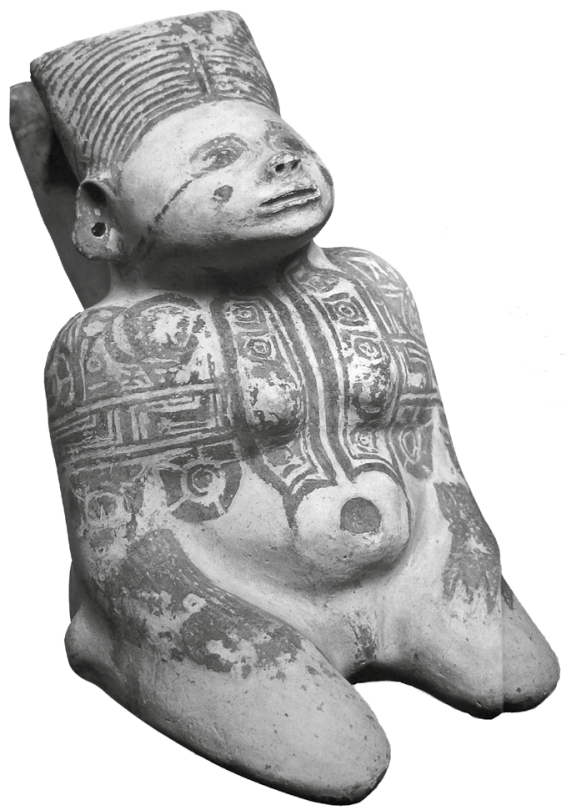

Figura 10 a y b. Figuras femeninas de terracota que dentro de su variedad reflejan rasgos inconfundiblemente huastecos. Llevan tocado sobre el cráneo deformado, tatuajes sobre el cuerpo y rostro y escarificación dentaria. Fuente: Los Huastecos. Revista Arqueología Mexicana, XIV(79), 53; c. Vasija efigie de mujer con tatuajes. Posclásico Tardío Tamaulipas MNA. Fuente: Los Huastecos. Revista Arqueologia Mexicana, XIV(79), 28. 

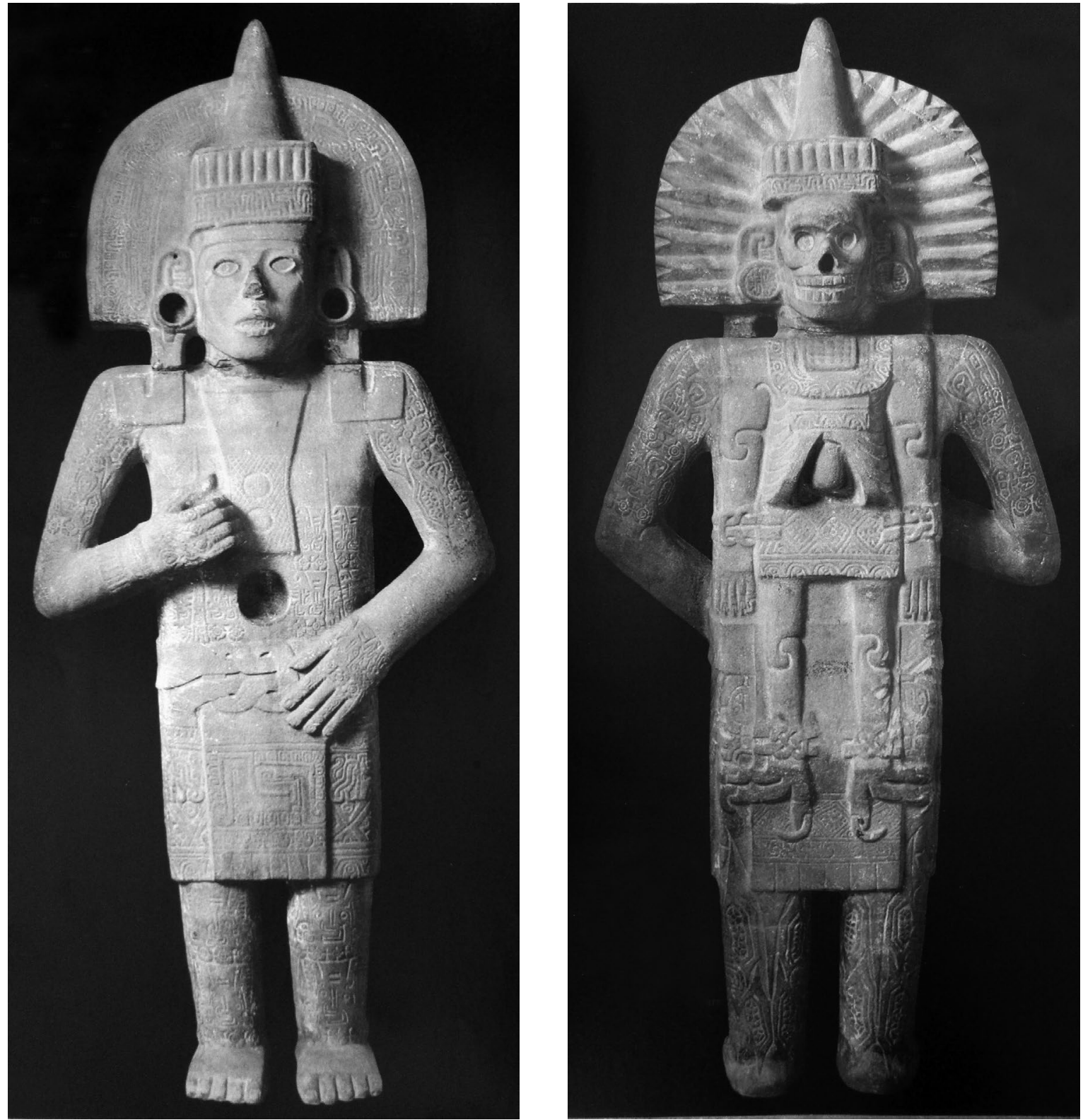

Figura 11 a y b. La Apoteosis. Posclásico. San Vicente Tancuayalab, San Luis Potosí. Museo de Brooklyn, NY. Fuente: Los Huastecos. Revista Arqueología Mexicana, XIV(79), 50-51.

femenina en el arquetipo universal. Dice Solares que esto responde al "simbolismo básico de la ecuación: mujer=cuerpo=vasija” (2007, p. 59), por lo que es inevitable también la asociación con las cuevas sagradas Bokoom "mohosidad" y "Madre" Bokoom, que según Ochoa (2003) "es el nombre de la deidad de la tierra y de la fertilidad. Por ser la gran dadora de vida, es una de las deidades supremas de los teenek" (p. 77). De acuerdo con lo anterior, algo hueco y oscuro como una vasija nos remite a las entrańas de la "Gran Madre".

Las vasijas efigie tatuadas son el medio artístico en el que la desnudez femenina se presenta en su totalidad corpórea. Esta técnica del arte huasteco sobre el cuerpo, la piedra y la cerámica fue sin duda realizada por alguien especializado en ello. No contamos con información suficiente que aporte más datos 
respecto de la aplicación de los tatuajes y el contexto en el que se desarrollaba; que muy probablemente fue ritual, como se constata con otros pueblos no occidentales alrededor del mundo. Por ello, puede considerarse una práctica universal en la que por medio de un ritual de paso se celebra, por ejemplo, la mayoría de edad de un individuo, hecho que en una sociedad de esta naturaleza era un indicador de que había llegado el momento de aparearse. El arte del tatuaje en el cuerpo tiene una historia de más de tres mil años, al igual que la antigua práctica de limar los dientes. Resulta una interesante coincidencia que tribus lejanas de latitudes distantes y los huastecos de América -entre otros- hayan compartido rasgos estéticos y religiosos tan similares. Esto refleja el gran valor que han dado al cuerpo humano para convertirlo en lenguaje narrativo de arte que expresa el imaginario cosmológico.

Los dibujos de las vasijas son uno de los testimonios de indudable belleza que nos indica que los huastecos lo aplicaron sobre su propio cuerpo. Otra prueba de ello se observa en algunas esculturas emblemáticas que evidencian la aplicación de dicha técnica, tanto en la parte frontal como en la posterior, de figuras masculinas tatuadas en su totalidad (Figura 11). De esta práctica, al parecer común entre los huastecos, se desconoce cuántas veces en el ciclo de vida pudo un individuo ser sometido a algún ritual que implicara tatuarlo. Sin embargo, se puede deducir que la cualidad de permanencia del tatuaje sobre la piel revistió importantes connotaciones simbólicas. La presencia de este tipo de arte en personajes relevantes de la mitología huasteca encontrados en la escultura y las vasijas, y el hecho de la desnudez tatuada, permite afirmar que el individuo al que se le practicaba era de clase noble o elegido entre el resto por alguna particularidad que lo habilitaba para ser 'marcado' de esta manera. Un tatuaje era una marca indeleble que se exhibía ante la sociedad y que, en su carácter religioso, pudo significar el acceso a un plano superior que permitía el contacto con alguna divinidad.

Retomemos la imagen de Tlazoltéotl como la gran paridora del universo y el acto de tatuar la piel; ambos nos evocan el fluir de la sangre al momento en que suceden, así como al dolor que, a su vez, significaba purificación. Estos dos eventos quizás puedan considerarse actos sacrificiales en los que se pone a prueba la resistencia y la valentía, dones preciosos que se ofrendaban a los dioses. Por lo tanto, el dolor producido por el tatuaje, además de las otras técnicas que ejercían para crear arte sobre el cuerpo, tuvo particular significado social, o de otro modo, no se puede pensar que la intervención estética por medios tan dolorosos haya tenido un fin únicamente estético. El sentido de la desnudez para los huastecos estaba en relación con lo que el cuerpo podía simbolizar y, en ocasiones, resistir.

En los estudios multidisciplinarios sobre el sistema artístico del México antiguo hay una amplia fundamentación simbólica sobre el porqué los pueblos ancestrales practicaban un tipo de arte y el porqué de los productos culturales que obtenían. Parece ser que el arte en la cosmovisión indígena tenía la función estética y cultural religiosa, y que, además, estaba claramente vinculado a la vida social y política de los pueblos. Es difícil pensar que estas sociedades hayan manifestado una forma de arte sencillamente por ocio, pues lo que alcanzamos a comprender sobre la historia de estos pueblos de origen remoto es una sistémica visión cosmológica.

A pesar del tratamiento asexuado que daban los artistas huastecos de la época a la figura femenina, esto pudo no tener importancia puesto que -a modo de hipótesis- resaltaron otros aspectos estéticos que sin duda expresaron la identidad de lo femenino. En este sentido, lo femenino, más allá de su aspecto anatómico, fue simbolizado más como soporte para el uso de la pintura, como se observa en la pintura del rostro de Tlazoltéotl, en un sistema indumentario cargado de significado y en el tatuaje de las vasijas antropomorfas.

Hemos mencionado algunos de los tipos de arte que hicieron de la desnudez un lenguaje particular para ser mostrado, testimoniados con la pintura y el tatuaje; no obstante, los huastecos implementaron otras técnicas más "invasivas" para expresar su cosmovisión de manera inalterable sobre el cuerpo. Un ejemplo de esto es la escarificación, ${ }^{5}$ una técnica que

5 Según la RAE, la palabra escarificación viene del in- 
permitió lograr diseños con volumen mediante una lesión sobre la piel que causaba un dolor profundo al practicarse con una herramienta punzocortante y que, al sanar, producía un dibujo creado a partir de una serie de cicatrices. Sin embargo, contrario al uso del tatuaje, se cuenta con pocos ejemplos que atestigüen el empleo constante de esta técnica.

Uno de los raros ejemplos de escarificación entre los huastecos fue hallado en el sitio arqueológico de Tamtoc. ${ }^{6}$ Los dibujos producidos por medio de esta técnica sobre hombros, pechos y muslos aparecen en una hermosa figura de torso femenino a la que se conoce como "Venus de Tamtok" o "Mujer Escarificada" (Figura 12). Se encontró decapitada, con el tronco del cuerpo mutilado en brazos y piernas a la altura de los muslos. Este vestigio escultórico muestra una protuberancia en forma de triángulo púbico en el área que corresponde a la vulva, además de pechos prominentes. Los estudios derivados de las excavaciones en el sitio donde fue encontrada apuntan lo siguiente:

\section{[...] escultura de bulto femenino con marcas} (en formas geométricas) de escarificaciones en muslos y hombros. Estas marcas son puntos sobresalientes del resto del cuerpo: los de los hombros, conformados en una banda, son 52, número emblemático relacionado con los ciclos calendáricos mesoamericanos; los que se encuentran en los muslos forman tres rombos sobrepuestos verticalmente y se tocan con la punta de sus ángulos (Salazar, Martínez y Córdova, 2012, p. 288).

Esta figura fue hallada en el fondo de un estanque y su forma evoca más el estilo de la escultura de Occidente antiguo por la forma del cuerpo y el acabado terso de la piel de "pulido perfecto" (Ibíd.). Una posible interpretación sobre los motivos geométricos en forma de rombos marcados en los muslos apunta a una relación con "el área nuclear olmeca como en

glés scar que quiere decir cicatriz. La escarificación es literalmente un corte doloroso regularmente superficial o profundo que a la postre producirá una cicatriz con relieve, que es la base de un diseño sobre la piel.

6 Está localizado en la región huasteca del estado de San Luis Potosí, México, en el municipio de Tamuín.

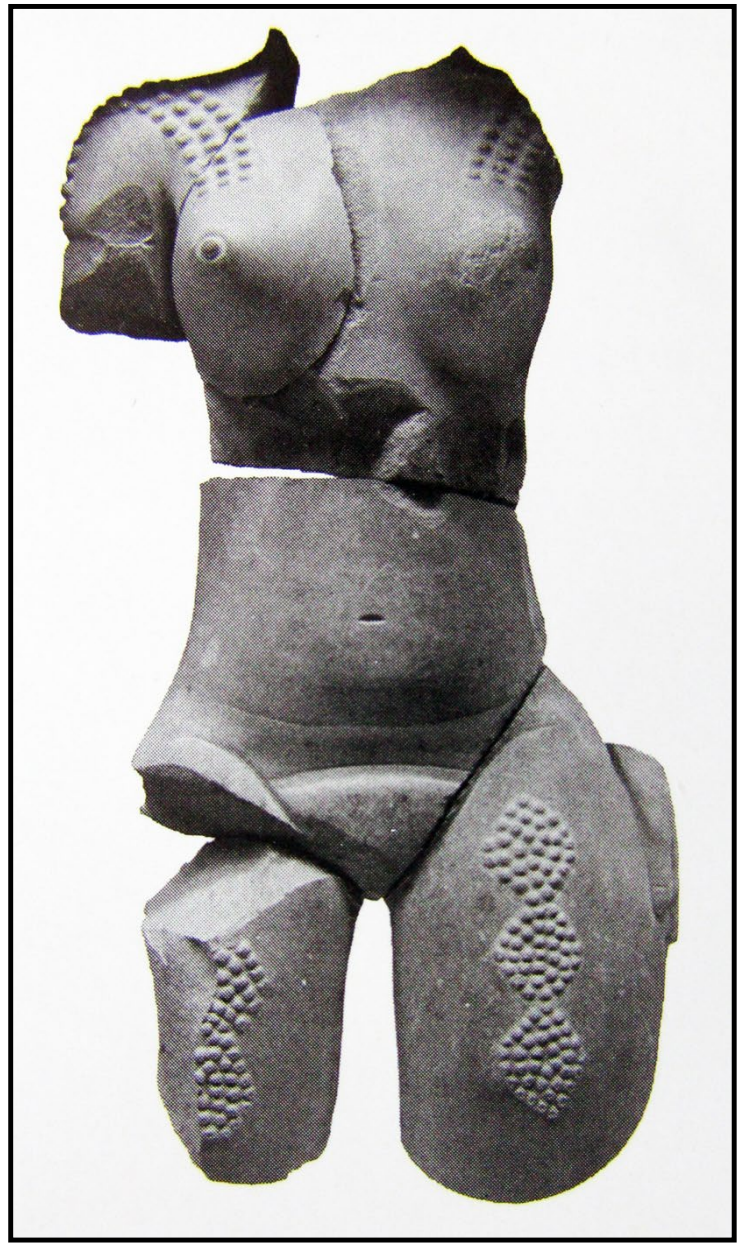

Figura 12. Mujer escarificada o Venus de Tamtok, San Luis Potosí, México.

el área maya y de manera tardía con la huasteca. Lo relevante en este caso es que los mismos motivos se han interpretado en el arte olmeca como representaciones de vegetación y en algunos casos específicos del maíz" (Ibíd., p. 289).

Esta lectura, dentro del contexto acuático de la ofrenda de la que la escultura formaba parte, parece también adecuada. Si lo que vemos en las piernas de La Mujer Escarificada son estos símbolos de vegetación, podríamos pensar que todo su significado está relacionado directamente, por la naturaleza de la mujer, con la fertilidad y la fecundidad. Este personaje podría representar los dos conceptos... (Ibíd.). 
Esta interpretación nos permite asociar simbólicamente lo planteado con anterioridad respecto al posible significado de las vasijas efigie como contenedoras de algún líquido, así como la importancia de los humedales y su vínculo con la condición femenina en la amplia cosmovisión mesoamericana. Otro aspecto relevante de destacar es el predominio de la forma del rombo en los dibujos producidos por la escarificación. Hemos detallado en otra obra que estudia el simbolismo de la vestimenta femenina de las mujeres del pueblo teenek de filiación huasteca, ${ }^{7}$ la importancia cosmológica de la figura del rombo en el quechquémetl que cubre el torso y que tradicionalmente ha tenido esta forma. Según la tradición oral de los teenek, esta prenda representa a la mujer porque resalta sus cualidades reproductoras. Ella misma representa al universo cuando viste de esta manera, por lo que constituye la personificación de la Gran Madre que rige al cosmos.

De lo anterior se desprende un amplio concepto relacionado con la forma del universo que está "dividido en cuatro cuadrantes y un área central ha sido compartido por los pueblos de origen mesoamericano en el denominado quinqunce que simboliza a los cuatro rumbos cósmicos" (Rocha 2014, p. 184), representados en la forma y en mucha de la iconografía labrada en el sistema indumentario (Figura 13 a y b).

\section{La vestimenta sagrada de la Madre Tierra}

La vestimenta indígena, como se concibió desde la época de los ancestros, estableció las pautas que nos permiten hoy identificar algunos de los rasgos primordiales que, con el devenir del tiempo y con los estudios emprendidos en torno a ella, han permitido construir una identidad de lo femenino de los pueblos de origen mesoamericano. En este sentido, podemos afirmar que los relatos indígenas sobre el vínculo mito-histórico que han tenido las mujeres con el tejido corresponden a un territorio vasto de la memoria del pensamiento simbólico, que a partir

7 La obra a la que nos referimos es Tejer el universo. El dhayemlaab, mapa cosmológico del pueblo teenek en dos tomos: Historia de una prenda sagrada y Cosmografía sagrada. San Luis Potosí: El Colegio de San Luis / Gobierno del Estado de San Luis Potosí (SECULT), 2014. de la tradición oral ha prevalecido desde los antepasados remotos hasta un período contemporáneo, a pesar de las transformaciones y fracturas de las tradiciones, particularmente, de la tradición oral.

Cabe destacar el origen sagrado de la actividad textil para comprender su importancia simbólica e histórica, partiendo del principio de que un objeto tejido es un producto emanado de la tierra, mismo principio que, en términos metafóricos, nos remite a la idea de que, para hacerla producir, la tierra debe ser 'penetrada u horadada' con el fin de depositar en ella una semilla que ha de germinar. De manera específica, la siembra del algodón, su cosecha y transformación hasta convertirse en una prenda eran procesos observados por los ciclos lunares que ancestralmente regían la actividad agrícola. En esta cosmovisión la luna sufría un proceso de vida y muerte a través de ocho fases en las cuales su transformación significativa se observaba en el ciclo de 29 días que comprende la luna nueva, el cuarto creciente, la luna llena y el cuarto menguante, para morir y renacer una y otra vez. Esta observación astronómica milenaria ha permitido asociar el ciclo menstrual de las mujeres con la siembra y la cosecha que simboliza la fertilidad femenina.

De esta manera, la menstruación y su connotación sexual de mujer fértil en su espectro reproductivo son un símil del numen de la Madre Tierra, que es también la luna, y que en su etapa productiva puede reproducir a su propia especie una vez fertilizado el vientre/tierra, cada vez que se presentan los períodos cíclicos de renovación de la vida en los cambios de las estaciones, mismos que en la cosmovisón mesoamericana estuvieron regidos y observados a gran escala por las temporadas de secas y las de lluvias, que a su vez significaban, cada cierto tiempo, la renovación de la tierra. Esta observación y comportamiento de los fenómenos naturales fueron interpretados y apropiados simbólicamente por estos pueblos en la figura de la Madre que gobierna sobre la vida que emana de ella. Así, desde los tiempos de los ancestros las mujeres se asocian a toda actividad fecundadora; son hijas de la luna y la noche, y por lo tanto, su condición es fría, el opuesto complementario al Padre Sol. 


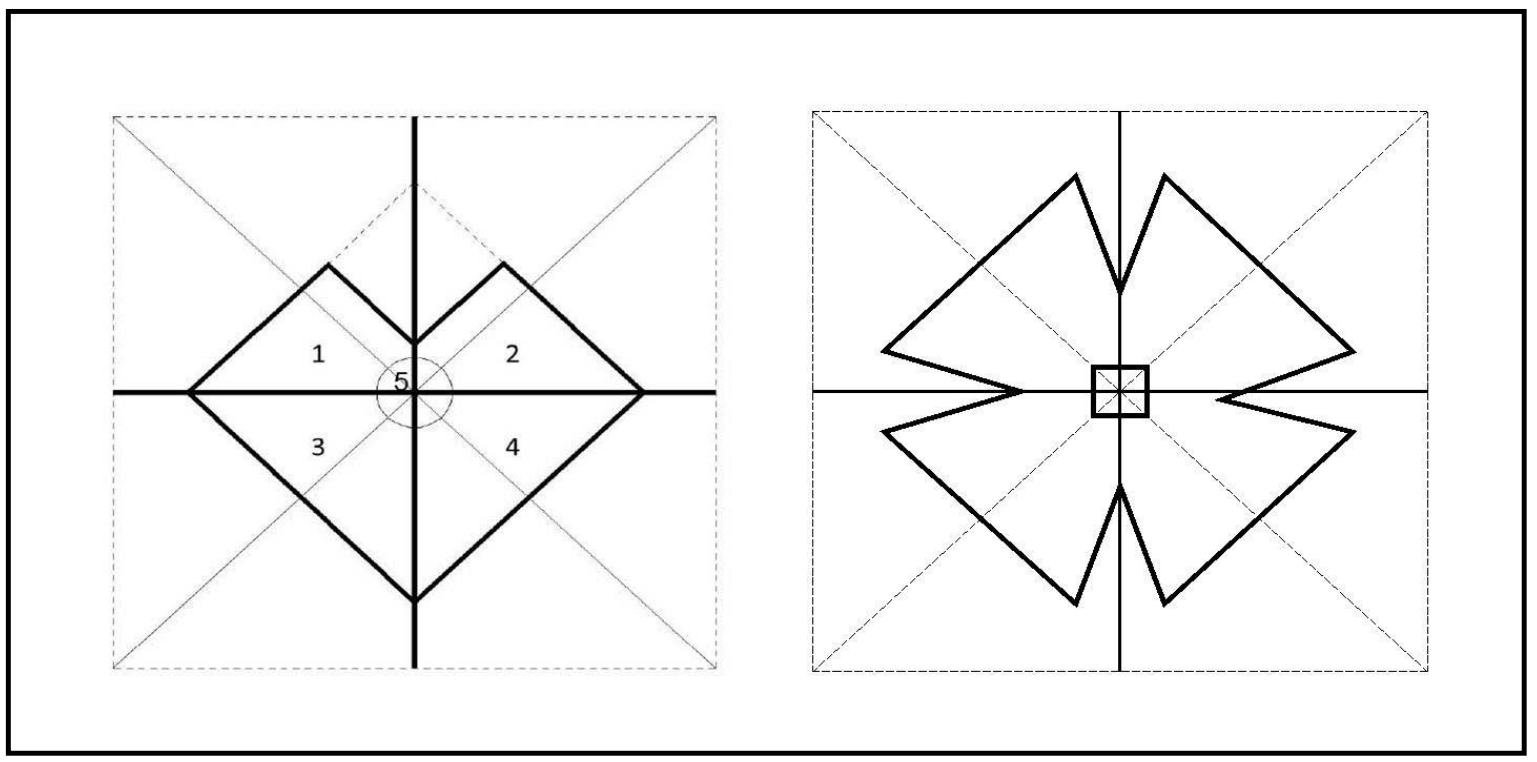

Figura 13 a y b. a) lado izquierdo: representación de los rumbos cósmicos en el quechquémetl teenek; b) lado derecho: la cruz de Quetzalcóatl o quincunce, representación del universo.

De esto se desprende que la tradición textil sea una actividad con diversos significados femeninos contenidos en un vasto repertorio mitológico que involucra personajes supremos y lugares del extenso territorio proveniente de la matriz cultural mesoamericana. Sobre ello podemos citar algunos hermosos ejemplos del cosmos femenino y el telar: "[...] la mujer que ha de dar a luz a los Gemelos está tejiendo cuando un pájaro pequeño (específicamente, un colibrí en una versión mixe) se sienta en su telar y ensucia la urdimbre. La muchacha lo mata con el tzotzopaztli, el machete del telar" (Ávila, 1996, p. 72). Por lo tanto, si la acción de tejer se consideraba una actividad cosmológica, inferimos que vestir estos tejidos significa habitar en ese universo y, por ende, pertenecer a ese orden sagrado. La actividad textil tuvo la función mítica de emparentar a las mujeres del plano terrestre con las diosas del universo. En la mitología mesoamericana, como ya vimos, destacó Tlazoltéotl y Xochiquétzal, que se representa frente a un telar montado en un árbol, que es el de la vida.

\section{La memoria en el cuerpo}

El acto de tejer fue en sí mismo sagrado, y pudo simbolizar además una forma de ritual femenino ofrecido a la Madre Tierra con la idea de mantenerla aquietada y lograr que respondiera a sus peticiones. Tejer fue uno de los caminos que el "destino" imponía como tarea. Visto así, se trató de una actividad obligatoria de la condición femenina en su sentido cosmológico. Servía también para equilibrar las fuerzas universales, según señalamos en el caso del pueblo teenek (Rocha, 2014, p. 197).

Por otro lado, la Madre Tierra representa el potencial y la capacidad destructora y constructora de lo femenino. Miim Tsabaal, como la llaman los teenek, manifiesta su exuberancia hídrica y vegetal desbordada a ratos, lo que evidencia su supremacía sobre lo humano y lo natural [...] Miim Tsabaal tiene múltiples funciones simbólicas como portadora de la fertilidad en un contexto preeminentemente vegetal al que son proclives los teenek en su cosmografía textil. La importancia del mundo de las plantas, la necesidad de éstas para su consumo como alimento y como símbolo en las sociedades agrícolas... (Ibíd.)

Además de la acción de tejer, existe un repertorio interesante de prácticas interconectadas simbólicamente entre el cuerpo humano y la tierra, que aluden a la fertilización. Entre los teenek y otros pue- 
blos es común observar que el ombligo de un recién nacido es enterrado; después, en el mismo sitio, es sembrada una planta de plátano, para que cualquier individuo mantenga su conexión primigenia con la Madre cósmica. Otro relato que apunta en el mismo sentido es el de una mujer ${ }^{8}$ que refiere que el primer dibujo que bordan al centro y abajo de su quechquémetl, es hecho cerca del ombligo, el centro equilibrador del cuerpo, el lugar por donde fluye el alimento y que, a su vez, está conectado orgánicamente a los genitales femeninos. Baste también el registro de otra tradición sobre la que algunos testimonios indican que tanto hombres como mujeres usan el quechquémitl como prenda de tránsito al momento de morir, para ser devueltos a la Tierra.

La confección, el uso y el simbolismo de la iconografía mítica bordada sobre el quechquémetl de las teenek son un ejemplo de cómo esta prenda, por su forma, representa a la mujer misma y al universo en sus cuatro rumbos cósmicos. Las figuras bordadas que dan identidad cosmográfica a las mujeres de este pueblo llevan nombres sugerentes relacionados con una cosmovisión que persiste gracias a una tradición oral y visual que ha trascendido los tiempos, pero que, a la vez, ha incorporado otros repertorios iconográficos. En estas figuras destacan los que denominan Madre Tierra, el Dios Maíz y el Dios Trueno (Figura 14), entre otros, además de un vasto mundo vegetal en el que habitan mariposas, aves y diversos animales presentes en un sistema cósmico que expresa su cosmovisión.

Hay varios elementos decorativos y prendarios del atuendo femenino que aparecen en el arte escultórico y cerámico. De entre ellos hemos destacado la falda o enredo (Figuras 1, 2, 3, 4, 10b y 14), y también el tocado, algunos con forma de gorro cónico, a veces truncado, y otras con un penacho sobresaliente en la parte posterior (Figuras 1, 4, 5a y b, 6 y 11). Otra forma que tuvo este tocado fue un rodete trenzado (Figuras 14 y 15) y que de acuerdo a la indumentaria contemporánea se confeccionaba con fibras vegetales de bejuco, algodón; posteriormen-

8 Com. pers. con María Francisca Donato de la cooperativa de artesanas Am tsájum ("Arañas Tejedoras"), Ejido de Tampate, Primera Sección, municipio de Aquismón, San Luis Potosí, México, noviembre de 2006. te, a partir de la colonización, se hicieron también de lana. ${ }^{9}$ Algunos datos que apuntan a su posible significado derivan de la palabra cuexhté en náhuatl -en la descripción de Meade (1942), "se compone de madejas de estambre de diversos colores que figura en la cabeza una especie de corona o cuexte" (p. 141) - y su relación lingüística con "Cuexteca", que fue el nombre del guerrero y líder mítico que guió a su pueblo -de aquí una de las posibles acepciones de la palabra huaxteca, que también alude a la forma en espiral de un caracol en el Dios del viento, una de las advocaciones de Quetzalcóatl, de filiación huasteca, sobre lo cual Johansson (2012) abunda al sugerir que cuechtli, "caracolillo", es un paradigma simbólico de la fertilidad y de la sexualidad en el mundo náhuatl prehispánico-.

En lengua teenek se denomina petob, que puede referirse a algo redondo o rodete, como el tocado que han usado las mujeres.

Sobre el tocado, Vásquez (2008) señala que los "atuendos incorporados a la cabeza constituyen un importante señalamiento del estado social, no solo referido a su posición económica, sino también a los casos de soltería, de enlace conyugal o a la situación de viudez en que se encontraba una persona (p. 51).

Éste es un significado que apunta al ámbito social y puede constatarse por los testimonios recogidos entre las mujeres indígenas de México que todavía usan el conjunto indumentario. Puede interpretarse que la condición conyugal mostrada en el tocado o por medio de otro elemento indumentario tiene una estrecha relación simbólica con el ciclo reproductivo de una mujer y de la Madre Tierra. No obstante, una interpretación cosmológica más específica es difícil de enunciar por la ausencia de información sobre el significado que tuvieron los tocados en el período prehispánico. Sin embargo, si tomamos en cuenta que éste ha sido un adorno confeccionado con algodón, encontramos el elemento que lo vincula al concepto general de la $\mathrm{Ma}$ dre Tierra; otro rasgo que lo vincula con lo anterior

9 En la Huasteca potosina hace más de cuatro décadas se introdujo la fibra de acrilán, un polímero sintético con el que se confecciona el tocado de manera generalizada entre las teenek en mazos de diferentes colores. 


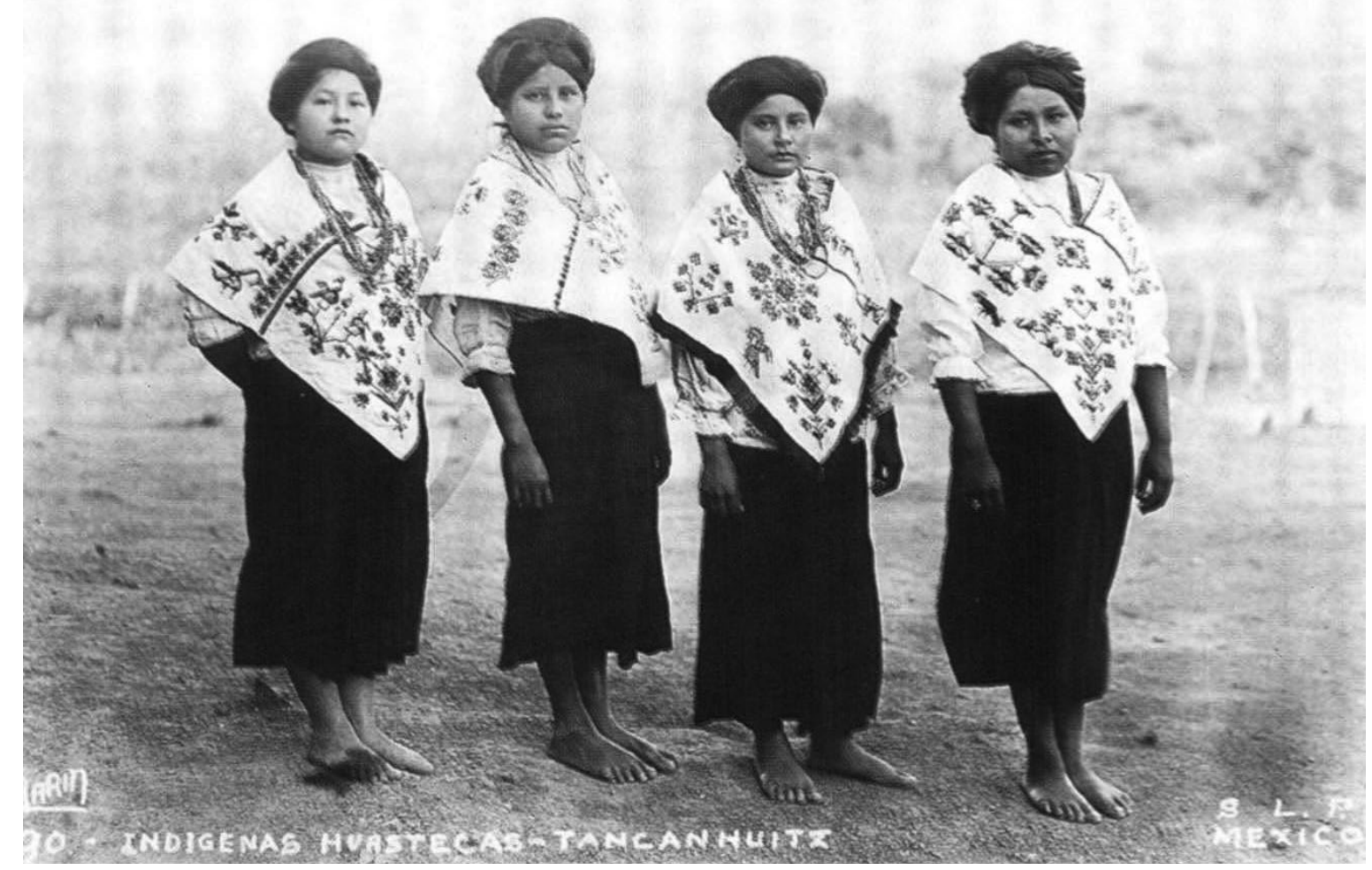

Figura 14. Indígenas teenek, Municipio de Tancanhuitz, San Luis Potosí, México, 1930. Autor desconocido.

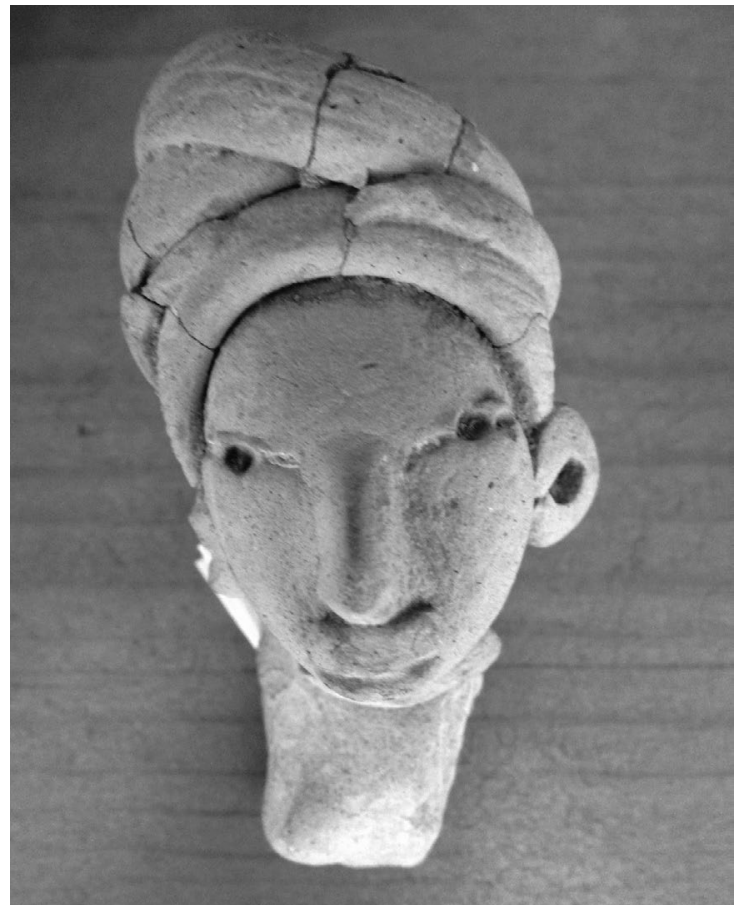

Figura 15. Cerámica de barro huasteca, San Luis Potosí, México. Colección particular. es que podemos considerarlo entre los elementos prendarios, puesto que al trenzarlo con el pelo se transforma en tejido, ya que las hebras se entretejen con los mazos de la fibra.

Pensemos que el tocado de las mujeres indígenas se ha "tejido" en la base de la cabeza, que supone la parte del cuerpo más alta. ¿No sería plausible interpretar que esto significa el contacto más directo con el plano celeste, con la Luna misma, por lo que entonces su ubicación lo coloca en un lugar importante de la cosmología indumentaria? El pelo largo de las mujeres indígenas también está asociado a la urdimbre del telar y a la lluvia, es decir, encontramos una adecuada correspondencia entre los hilos, sean éstos cabello, algodón u otra fibra, y su relación con la fertilidad.

Brenner (1986) señala: "La tierra es el punto de referencia de toda actividad, la vagina y vientre ancestral, el material que contiene toda vida y define costumbres. Es, asimismo, el alma y manantial fundamental de su especulación, su norma y su arte" 
(p. 116). La tierra es origen y destino último al cual habrá que regresar eventualmente, como el ombligo "sembrado", como el quechquémetl mortuorio.

\section{Conclusiones}

Hablamos no del cuerpo erotizado, sino de la significación histórica, antropológica y arqueológica que los pueblos del México antiguo dieron al cuerpo desnudo femenino para simbolizarlo. Encontramos en la actualidad solo los rastros de una vestimenta de origen cósmico, y en cuanto a las otras formas de arte indígena que adornaron alguna vez la desnudez, apreciamos que se extinguieron con el tiempo y el desuso impuesto por las prohibiciones religiosas bajo la égida de la ideología cristiana, que castigaba severamente la desnudez y los adornos sobre ésta en lo que corresponde al tatuaje y la escarificación, además de la deformación craneal y el limado dental, técnicas sobre las que se expuso someramente en este texto, por lo que se considera necesario ahondar en la investigación de dichas prácticas con el propósito de enriquecer el simbolismo estético que los pueblos antiguos de México dieron a esta forma de simbolizar y embellecer el cuerpo.

Llama la atención que los herederos de esas sociedades tan antiguas, diluidas y transformadas con el tiempo, sean culturas vivas y dinámicas en esta primera mitad del siglo XXI. Estas sociedades contemporáneas indígenas que a veces parecen tener poco que ver con sus antepasados, con nulo acceso a documentos pictóricos como los códices, las esculturas y cerámica producidas por sus antepasados, a los sitios arqueológicos de sus abuelos abiertos a todo público y que raramente visitan. A pesar de ello, la memoria del pensamiento simbólico indígena es perseverante, se resignifica constantemente en cada acto ritual, en cada vestimenta que aún se confecciona. Aunque desconozcan la historia del tatuaje, la escarificación, a Tlazoltéotl y toda la producción artística de sus antepasados, conocen, sin que nadie se los diga, la memoria que guarda el cuerpo para vestirlo y ritualizarlo.

Algunos siguen ofrendando a sus "dioses" o "dueńos" de un universo cada vez más reducido o transformado. Siguen ofrendando a una Madre Tierra que se agota por la sobreexplotación de sus veneros, pero que de muchas formas se mantiene vigente como símbolo de las fuerzas naturales y de los entes sobrenaturales que la representan.

\section{Referencias citadas}

Ávila B, A. (1996). La hilandera y los gemelos. Arqueología Mexicana, 3(17), 72.

Brenner, A. (1983). Ídolos tras los altares. México: Domés.

De la Fuente, B. y Gutiérrez Solana, N. (1980). Escultura huasteca en piedra. México: UNAM.

Estévez, A. El cuerpo como patrimonio: ¿̨una cuestión ética? En Primeras Jornadas Internacionales de Ética "No matarás", Facultad de Filosofía, Historia y Letras, Universidad del Salvador, Buenos Aires, 17, 18 y 19 de mayo del 2000. Recuperado de www.unesco.org.uy/mab/fileadmin/shs/ rediotecica/Estevez_El_cuerpo_como_patrimonio.html

Jiménez López, L. (1993). Cómo la luna nos enseñó a tejer. Artes de México, 19, 40.

Johansson KEraudren, P. (2012). La imagen del huasteco en el espejo de la cultura náhuatl prehispánica. Estudios de Cultura Náhuatl, 44, 65-133. Recuperado de www. historicas.unam.mx/publicaciones/revistas/nahuatl/pdf/ ecn44/910.pdf

Ladrón de Guevara, S. y Beverido, M. (Eds.). (2008). Mujeres de antaño, presencias y omisiones (pp. 33-40). Xalapa: Museo de Antropología de Xalapa.

Luján Pinelo, J. (2008). Feminidad, culto y cotidianidad en la Huasteca. En Ladrón de

Guevara, S. y Beverido, M. (Eds.). Mujeres de antaño, presencias y omisiones (pp. 33-40). Xalapa: Museo de Antropología de Xalapa.

Meade, J. (1942). La Huasteca. Época antigua. México: Cossío.

Ochoa, Á. (2003). Significado de algunos nombres de deidad y de lugar sagrado entre los teenek potosinos. Estudios de cultura maya, 33, 73-94.

Rocha, C. (2014). Tejer el universo, el dhayemlaab, mapa cosmológico del pueblo teenek, obra en dos tomos: Historia de una prenda sagrada y Cosmografía sagrada. San Luis 
Potosí: El Colegio de San Luis / Gobierno del Estado de San Luis Potosí (SECULT).

Ruiz de la Cruz, M. del P. y Bautista Pérez, J. C. (2012). Consideraciones preliminares de los materiales cerámicos de Tamtoc. En Córdova Tello, G., Martínez Mora, E. y Hernández, P. (Coords.). Tamtoc. Esbozo de una antigua sociedad urbana (pp. 301-330). México: INAH.

Salazar Lama, D., Martínez Mora, E. y Córdova Tello, G. (2012). Espacios sagrados en Tamtoc. El caso del monumento de La Sacerdotisa y su entorno. En Córdova Tello, G., Martínez Mora, E. y Hernández, P. (Coords.). Tamtoc. Esbozo de una antigua sociedad urbana (pp. 269299). México: INAH.

Solares, B. (2007). Madre Terrible, La Diosa en la religión del México Antiguo. México: Anthropos / UNAM.

Vásquez Zárate, S. (2008). Los peinados y los tocados como indicadores de diferenciación. En Ladrón de Guevara, S. y Beverido, M. (Eds.). Mujeres de antaño. Presencias y Omisiones (pp. 49-58). Xalapa: Museo de Antropología de Xalapa. 
